\title{
Assessment of adiposity in psoriatic patients by dual energy $X$-ray absorptiometry compared to conventional methods ${ }^{*}$
}

\author{
Michelle dos Santos Diniz ${ }^{1,2}$ \\ Adriana Maria Kakehasi ${ }^{1}$ \\ Maria Marta Sarquis Soares ${ }^{1}$
}

\author{
Nádia Couto Bavoso ${ }^{2}$ \\ Márcio Weissheimer Lauria ${ }^{1}$ \\ Jackson Machado-Pinto ${ }^{2,3}$
}

DOI: http://dx.doi.org/10.1590/abd1806-4841.20164082

\begin{abstract}
BACKGROUND: Obesity is considered a chronic low-grade inflammatory disease that shares mediators of inflammation with psoriasis, such as TNF- $\alpha$ and IL-6. The relationship between these two conditions involves factors such as predisposition and response to therapy, in addition to an association with cardiovascular disease. ОвјестіVEs: The aim of the present study was to investigate the prevalence of adiposity as determined by body mass index (BMI), waist circumference (WC), and dual energy X-ray absorptiometry (DXA) evaluation in patients with psoriasis.

METHODS: BMI, WC and body composition by DXA were measured in 42 psoriatic patients without joint complaints and in 41 control patients using standard procedures. In the comparison between cases and controls, we used Pearson's X2 test or Fisher's exact test, and the nonparametric Mann-Whitney test. The difference between the diverse classification methods for obesity was evaluated using McNemar's test. To test the level of agreement between those variables, we used the weighted kappa coefficient.

RESULTS: There was no difference in the prevalence of obesity among cases and controls. Both BMI and WC had low agreement with measures of body fat evaluated by DXA. With the use of DXA scanning, prevalence of overweight and obesity in patients with psoriasis was $83.3 \%$, which constitutes a strong evidence of the need for intervention on this metabolic parameter.

ConcLusion: Dual energy X-ray absorptiometry was more capable of identifying obesity compared with BMI and WC both in psoriatic and control patients.
\end{abstract}

Keywords: Abdominal circumference; Body mass index; Densitometry; Obesity; Psoriasis; Waist circumference

\section{INTRODUCTION}

Psoriasis is a chronic immune-mediated inflammatory disease affecting 1-3\% of the world population. Several studies have demonstrated the association of psoriasis with obesity and metabolic syndrome. ${ }^{1-3}$ Obesity is considered a chronic low-grade inflammatory disease that shares with psoriasis mediators of inflammation such as TNF- $\alpha$ (Tumor Necrosis Factor alpha) and IL-6 (Interleukin 6). 2,4 The relationship between these two conditions involves factors such as predisposition and response to therapy, in addition to an association with cardiovascular disease.
In general, body mass index (BMI) is used to classify underweight, normal weight, overweight, and obesity in patients. The measurement of waist circumference (WC) is also a useful tool, since abdominal fat is correlated with increased cardiovascular risk. ${ }^{5}$

Dual energy $\mathrm{X}$-ray absorptiometry (DXA) is a noninvasive method with the ability to evaluate body composition (lean mass and fat mass) with accuracy and precision, and with exposure to low doses of radiation, which enables the diagnosis of obesity comprising the assessment of the abdominal region. ${ }^{6-8}$ DXA technique is based on the premise that the body con-

Received on 01.10.2014.

Approved by the Advisory Board and accepted for publication on 02.06.2015.

Study performed at Santa Casa de Belo Horizonte and Centro de Especialidades Médicas (CEM) - Belo Horizonte (MG), Brazil.

Financial Support: This work received financial support from Janssen pharmaceutical industry, and FAPEMIG (Fundação de Amparo à Pesquisa o Estado de Minas Gerais).

Conflict of Interest: None.

Universidade Federal de Minas Gerais (UFMG) - Belo Horizonte (MG), Brazil.

Santa Casa de Belo Horizonte - Belo Horizonte (MG), Brazil.

Faculdade de Ciências Médicas de Minas Gerais (FCMMG) - Belo Horizonte (MG), Brazil.

(C)2016 by Anais Brasileiros de Dermatologia 
sists of three compartments, fat, bone, and lean mass, distinguishable by the property of differential X-ray attenuation. ${ }^{9,10}$ This is a relatively new method to determine body composition, which can estimate body adiposity with a small margin of error. ${ }^{8,11}$

The aim of the present study was to investigate the prevalence of adiposity as determined by BMI, $\mathrm{WC}$, and DXA evaluation in patients with psoriasis.

\section{METHODS}

The experimental arm was composed of adult patients with clinical and/or histopathological diagnosis of psoriasis, without joint complaints, assisted at the Dermatology Outpatient Clinic of Santa Casa de Belo Horizonte. All the patients were evaluated by an expert in the diagnosis and treatment of psoriasis. We established the following exclusion criteria: 1) postmenopausal women; 2 ) men aged $>70$ years; 3 ) smokers; 4) alcohol dependents; 5) presence of other chronic inflammatory diseases; 6) report or confirmed diagnosis of neoplasia or HIV infection; 7) use of systemic retinoids in the previous 12 months; 8) current use of systemic glucocorticoids, insulin, statins, growth hormone, anabolic agents, or hormone replacement therapy; 9) pregnancy or lactation, and 10) vitamin-D intoxication.

The control group comprised voluntary patients without psoriasis or any inflammatory disease, matched by sex and age, which were assisted at the Dermatology Outpatient Clinic of Santa Casa de Belo Horizonte.

Demographic and anthropometric data were obtained from an interview and physical examination of the participants, all of which performed by one of the investigators. Information regarding the presence of comorbidities and medication use were also collected.

The subjects were weighed in light clothing and with no shoes on a Filizola human weighing scale with $200 \mathrm{~kg}$ capacity and $0.05 \mathrm{~kg}$ accuracy. The height of the participants was determined using a mechanical scale-mounted stadiometer. We calculated BMI by the formula BMI = weight $(\mathrm{kg}) /$ height $(\mathrm{m}) 2$ and using the parameters established by the World Health Organization (WHO). ${ }^{12}$
WC was determined using a measuring tape placed in a horizontal plane around the abdomen, at the midpoint between the last rib and the iliac crest, with the subject in the orthostatic position and at the end of a normal expiration. WC $<88 \mathrm{~cm}$ for women and $<102 \mathrm{~cm}$ for men were considered normal. ${ }^{13}$

Body composition was evaluated by DXA scanning on a Discovery $W$ model DXA scanner (Hologic Bedford, MA, USA), software version 3.3.01, and interpreted by a single trained investigator. The scans were performed after a 12-h NPO fast (i.e., no food or liquids), with the subject in supine position after all his or her metal accessories had been removed. The percentage of total-body fat was calculated by the ratio of total fat mass/ total body mass. Obesity as determined by the DXA evaluation of percentage of body fat was classified according to the criteria enumerated in table 1.

We performed a descriptive analysis of the study variables. Kolmogorov-Smirnov normality test was conducted to test the normality of continuous variables and all had asymmetrical distribution. In the comparison between cases and controls, we used Pearson's X2 test or Fisher's exact test to compare categorical variables, and the nonparametric Mann-Whitney test to analyze numeric variables. The difference among the various methods used for obesity classification, BMI, WC, and DXA-determined percentage of body fat, was evaluated using McNemar's test. To test the level of agreement between those variables, we used the weighted kappa coefficient. ${ }^{14,15}$ We adopted a level of statistical significance of $5 \%$. Analyses were performed with the aid of the SPSS (Statistical Package for the Social Sciences) software version 15.0.

The present study was approved by the ethics committee of our institution; all patients provided written informed consent.

\section{RESULTS}

In the period from May to November 2012, this study included 42 patients with psoriasis and without joint complaints. The median age of these patients was 47 years, and $25(59.5 \%)$ of them were male. The mean reported disease duration was 10.00 years (interquartile range 5.00-20.00 years). Thirty-seven patients

TABLE 1: Cut-off points of body fat percentage for men and women ${ }^{11}$

\begin{tabular}{lllllllll}
\multirow{3}{*}{ Age (years) } & \multicolumn{3}{l}{ Women (\% of body fat) } & \multicolumn{5}{l}{ Men (\% of body fat) } \\
\cline { 2 - 9 } & $\begin{array}{llllllll}\text { Under } \\
\text { weight }\end{array}$ & $\begin{array}{l}\text { Normal } \\
\text { weight }\end{array}$ & $\begin{array}{l}\text { Over } \\
\text { weight }\end{array}$ & Obese & $\begin{array}{l}\text { Under } \\
\text { weight }\end{array}$ & $\begin{array}{l}\text { Normal } \\
\text { weight }\end{array}$ & $\begin{array}{l}\text { Over } \\
\text { weight }\end{array}$ & Obese \\
\hline $20-39$ & $<21$ & $21-32$ & $33-38$ & $39+$ & $<8$ & $8-20$ & $21-25$ & $26+$ \\
$40-59$ & $<23$ & $23-34$ & $35-40$ & $41+$ & $<11$ & $11-22$ & $23-28$ & $29+$ \\
$60-79$ & $<25$ & $25-37$ & $36-42$ & $43+$ & $<13$ & $13-24$ & $25-30$ & $31+$ \\
\hline
\end{tabular}


(88\%) had mild psoriasis as defined by PASI (Psoriasis Area Severity Index). We included a group of 41 control patients whose median age was 38 years, with $22(53.7 \%)$ male individuals. There was no difference between the groups in relation to sex $(P=0.590)$ and age $(\mathrm{P}=0.090)$.

Median values of BMI, WC and DXA-determined percentage of body fat for case and control groups were $26.7 \mathrm{~kg} / \mathrm{m} 2$ vs. $26.7 \mathrm{~kg} / \mathrm{m} 2(\mathrm{P}=0.913)$, $96.0 \mathrm{~cm}$ vs. $95.0 \mathrm{~cm}(\mathrm{P}=0.956)$, and $33.6 \%$ vs. $33.7 \%(\mathrm{P}$ $=0.774$ ), respectively (Table 2$)$.

Fourteen $(38.9 \%)$ patients with psoriasis had normal BMI while 13 (36.1\%) were overweight, and 9 (25\%) patients were classified as obese. According to the DXA-determined body composition, $6(16.7 \%)$ of the psoriasis patients were classified as having normal weight, $14(38.9 \%)$ as overweight, and $16(44.4 \%)$ as obese. The difference between these two classification modalities was significant $(P=0.004)$.

Regarding the control group, BMI identified 1 $(2.7 \%)$ underweight patient, $11(29.7 \%)$ patients with normal weight, 17 (45.9\%) overweight, and 8 (21.6\%) obese. According to DXA scans, 3 (8.1\%) patients in the control group were classified as having normal weight, $13(35.1 \%)$ as overweight, and $21(56.8 \%)$ as obese. In this group, there was also a statistically significant difference between the two obesity classification rates $(\mathrm{P}<0.001)$. The obesity classification for case and control groups is shown in table 3.
When we grouped overweight and obese patients, we observed that, based on the BMI, 22 (61.1\%) patients had weight excess, while according to the DXA-defined classification, the number of these patients rose to $30(83.3 \%)(\mathrm{P}=0.021)$. This means that $>20 \%$ of the patients had been classified as normal weight when in fact they were overweight or obese. The agreement between the two classification methods was only 0.348 , or $34.8 \%$, by the kappa coefficient (Table 4). When the group was stratified by sex, only a slight agreement was observed for male patients $(\mathrm{k}=0.087$ or $8.7 \%)$ and moderate agreement for female patients ( $\mathrm{k}=0.587$ or $58.7 \%$ ). The control group showed fair agreement between the two classification modalities ( $\mathrm{k}=0.311$ or $31.1 \%$ ) (Table 4$)$. By the BMI, 25 $(67.6 \%)$ control patients had excess weight while by the DXA-defined, it reached 34 (91.9\%) subjects. The stratified analysis by sex yielded a coefficient of agreement of 0.273 (or $27.3 \%$ ) for male patients and of 0.32 (or $32 \%$ ) for female patients in the control group (Table 4).

Considering WC, 17 (48.6\%) patients with psoriasis presented altered WC. There was a statistically significant difference in the prevalence of obesity regarding the classification by DXA $(\mathrm{P}<0.001)$. The agreement between elevated WC and overweight rating (overweight/ obesity) by DXA was low (kap$\mathrm{pa}=0.327$ ) (Table 4$)$. The analysis by sex shows a concordance of $0.122(12.2 \%)$ in male patients and of 0,706 $(70.6 \%)$ in female patients, presenting a good agree-

TABLE 2: Demographic and clinical characteristics of patients with psoriasis $(n=42)$ and control patients $(n=41)$

\begin{tabular}{llll}
\hline Variable & Psoriasis & Control & P Value \\
\hline Men (\%) & $25(59.5)$ & $22(53.7)$ & 0.590 \\
Age in years* & $47.0(33.8-54.3)$ & $38.0(29.5-49.0)$ & 0.090 \\
BMI kg/m2* & $26.7(23.8-30.7)$ & $26.7(24.5-28.7)$ & 0.913 \\
Abdominal circumference in cm* & $96.0(85.5-103.0)$ & $95.0(88.3-101.5)$ & 0.956 \\
Percentage of total fat by DXA $(\%)^{*}$ & $33.6(29.5-38.9)$ & $33.7(29.8-39.3)$ & 0.774 \\
\hline
\end{tabular}

* median and interquartile range; \# $\mathrm{n}=36$ cases and 37 controls

TABLE 3: Comparison of obesity classifications by BMI and by percentage of fat mass by DXA.

\begin{tabular}{|c|c|c|c|c|c|c|c|c|}
\hline \multirow[t]{3}{*}{ BMI } & \multicolumn{8}{|c|}{ Percentage of body fat by DXA } \\
\hline & \multicolumn{2}{|c|}{ Normal Weight } & \multicolumn{2}{|c|}{ Overweight } & \multicolumn{2}{|l|}{ Obese } & \multicolumn{2}{|l|}{ Total } \\
\hline & $\mathrm{PSO}^{*}$ & Control\& & $\overline{\mathrm{PSO}^{*}}$ & Control\& & $\mathrm{PSO}^{*}$ & Control\& & $\overline{\mathrm{PSO}^{*}}$ & Control\& \\
\hline Underweight & 0 & 1 & 0 & 0 & 0 & 0 & 0 & 1 \\
\hline Normal Weight & 5 & 2 & 6 & 6 & 3 & 3 & 14 & 11 \\
\hline Overweight & 1 & 0 & 6 & 6 & 6 & 11 & 13 & 17 \\
\hline Obese & 0 & 0 & 2 & 1 & 7 & 7 & 9 & 8 \\
\hline Total & 6 & 3 & 14 & 13 & 16 & 21 & 36 & 37 \\
\hline
\end{tabular}

* $\mathrm{n}=36 ; \quad \& \mathrm{n}=37$ 
TABLE 4: Agreement by kappa index between the different obesity classifications (BMI, WC and DXA)

\begin{tabular}{|c|c|c|c|c|c|c|}
\hline & \multicolumn{2}{|l|}{ BMI x DXA } & \multicolumn{2}{|l|}{ WC $\times$ DXA } & \multicolumn{2}{|l|}{ WC $\times$ BMI } \\
\hline & Kappa index & P value & Kappa index & P value & Kappa index & P value \\
\hline \multicolumn{7}{|l|}{ Case* $^{*}$} \\
\hline Male & 0.087 & 0.599 & 0.122 & 0.243 & 0.394 & 0.027 \\
\hline Female & 0.587 & 0.013 & 0.706 & 0.004 & 0.881 & $<0.001$ \\
\hline Total & 0.348 & 0.014 & 0.304 & 0.011 & 0.575 & $<0.001$ \\
\hline \multicolumn{7}{|c|}{ Control $^{\&}$} \\
\hline Male & 0.273 & 0.076 & 0.055 & 0.452 & 0.288 & 0.054 \\
\hline Female & 0.320 & 0.072 & 0.485 & 0.020 & 0.231 & 0.311 \\
\hline Total & 0.311 & 0.009 & 0.170 & 0.063 & 0.226 & 0.116 \\
\hline
\end{tabular}

BMI: Body Mass Index; WC: Waist Circunference; DXA: Dual energy X-ray absorptiometry

* $\mathrm{n}=36 ; \& \mathrm{n}=37$

ment in this group. In the control group, 19 (51.4\%) patients presented altered WC, while by DXA classification, 34 (91.9\%) patients were overweight $(\mathrm{P}<0.001)$. The agreement of the two measures was only of $17 \%$, determined by kappa (0.017). The analysis by gender shows a concordance of $0.055(5.5 \%)$ in male patients and of $0.485(48.5 \%)$ in female patients.

As noted from data shown above, both BMI and WC showed poor agreement with the body fat measures assessed by DXA. However, there was no difference between the classifications of obesity by BMI and WC in both case $(p=0.180)$ and control $(p=0.077)$ groups. The agreement of the two methods (BMI and WC) by kappa in patients with psoriasis was moderate (0.575). When stratified by sex, female patients showed good agreement (0.881) and male patients showed low agreement (0.394). In the control group the global agreement $(0.226)$ was low, such as the agreement in the female (0.231) and male (0.288) groups.

\section{DISCUSSION}

In the present study, the prevalence of overweight and obesity according to BMI, both in the group of patients with psoriasis $(61,1 \%)$ and in the control group $(67,5 \%)$, was greater than the prevalence based on WHO data, which showed $46 \%$ of overweight and obese adults. ${ }^{16}$ The prevalence of overweight and obesity found is also superior to the data from the Vigitel study. ${ }^{17}$ According to this study, a survey held in 27 Brazilian cities, the prevalence of overweight and obesity (BMI $\geq 25 \mathrm{~kg} / \mathrm{m} 2$ ) in the city of Belo Horizonte-MG, where the study was conducted, reached $48.1 \%$. However, some considerations are necessary: the prevalence of overweight/ obesity increases with age, reaching approximately $60 \%$ in 35-55 years patients, that is the mean age of the study population, and also increases with lower level of education ( $<8$ years of schooling). The subjects are from a population of low socioeconomic status and low level of education, thus the findings of our study do not seem to be so superior to that observed in the general population of the same age and level of education. Studies of psoriasis show prevalence rates of overweight and obesity defined by BMI of $51.8 \% .^{18}$

In contrast to several studies revealing higher prevalence of obesity in patients with psoriasis relative to the general population, our study showed no difference between psoriatic and control patients using the three obesity classification methods (BMI, WC, and DXA-determined percentage of body fat). ${ }^{5,19-}$ ${ }^{22}$ Nevertheless, more recent studies, such as Kim \& Lee's study, support our results, as those studies found no significant difference in BMI between patients with psoriasis and control patients. ${ }^{18}$

The percentage of patients with psoriasis and raised WC measures (48.6\%) was inferior to that of a large cohort (62.9\%). ${ }^{23}$ By contrast, control patients showed comparable values to those of the NHANES (National Health and Nutrition Examination Survey) study, in which large WC measures were found in $47.9 \%$ of the controls. ${ }^{23}$

Classifications of obesity by BMI and by WC showed no significant difference, as demonstrated by Lauria et al. However, both rates showed low agreement with the measures of body fat as evaluated by the DXA technique. Flegal et al also demonstrated that BMI and WC present better correlation with each other than with DXA-determined percentage of body fat. In addition, those authors showed that BMI and WC give an inadequate measure of percent body fat, when compared with DXA. ${ }^{24,25}$

For many decades, the BMI was the predominant index in the evaluation of obesity due to its simplicity and low cost. However, this is a method that does not take into account several obesity-related factors, such as muscle mass, bone structure, age, sex, and ethnic group., ${ }^{4,11,26}$ Although WC provides a simple measure of central fat deposition, which is a bet- 
ter predictor of adverse cardiovascular events, it also failed to provide a reliable measure of obesity compared with DXA.

DXA technique is considered superior in the assessment of body composition with precision of $\sim 99 \%$ in the estimation of soft tissue composition. ${ }^{11,22,26,27}$ With the use of DXA scanning, the prevalence of overweight and obesity in the patients with psoriasis reached $83.3 \%$, which constitutes a strong evidence of the need for intervention on this metabolic parameter. Psoriasis is currently seen as a multi-system inflammatory disease that shares immunologic characteristics with other diseases such as obesity, hypertension, diabetes, depression, and inflammatory bowel disease. ${ }^{1,5,21,28-30}$

There seems to be a reciprocal influence between obesity and psoriasis. ${ }^{20}$ Excess adipose tissue induces a chronic proinflammatory state with increased C-reactive protein and cytokines, such as TNF- $\alpha$ and IL-6, which not only promotes the development of cutaneous lesions, but also impairs the patient's response to systemic treatments. ${ }^{19,21,29,31}$ Moreover, psoriasis, with the metabolic deregulation coupled with the impairment in quality of life, sedentary lifestyle and poor eating habits, favors weight gain. ${ }^{31,32}$

Because of the high prevalence of comorbidities such as obesity in patients with psoriasis, a multi-system approach and particular attention to cardiovascular risk factors are warranted. Several authors have demonstrated an increased risk of atherosclerosis, acute myocardial infarction, and stroke in this group of patients..$^{33-35}$ One of the treatment goals for patients with psoriasis should be the reduction of obesity and, consequently, of the systemic inflammatory process. 30-32 The greater ability of DXA to identify patients with excess body fat - and, therefore, with greater cardiovascular risk - demonstrated in the present study highlights the importance and utility of DXA scanning for psoriatic patients.

Our study has limitations, such as the sample size that does not allow for a generalization of the results to the general population - although it suffices to contribute to elucidate the relationships between the different metabolic evaluation methods in psoriasis. It is noteworthy that this is the first study that compares the different methods of assessing obesity including DXA in patients with psoriasis. Furthermore, to date, no Brazilian parameters have been established for the classification of DXA-determined percentage of body fat; therefore, the international classification was used in our study.

\section{CONCLUSION}

Dual energy X-ray absorptiometry found higher prevalence of obesity when compared to BMI and WC in both psoriatic and control patients. Raised WC values showed a good agreement with the diagnosis of obesity only in female patients with psoriasis. There was no difference in the prevalence of obesity among psoriatic and control patients.

The adoption of obesity assessment through more accurate techniques such as DXA, especially for groups of patients particularly more susceptible to cardiovascular events, is a challenge to be faced over the coming future. 


\section{REFERENCES}

1. Wells JCK, Fewtrell MS. Measuring body composition. Arch Dis. 2006;9:612-7.

2. Farias MM, Serrano V, de la Cruz C. Psoriasis y obesidade: revisión y recomendaciones práticas. Actas Dermosifilogr. 2011;102:505-9.

3. Alsufyani MA, Golant AK, Lebwohl M. Psoriasis and the metabolic syndrome. Dermatol Ther. 2010;23:137-43.

4. Sterry W, Strober BE, Menter A; International Psoriasis Council. Obesity in psoriasis: the metabolic, clinical and therapeutic implications. Report of an interdisciplinary conference and review. Br J Dermatol. 2007;157:649-55.

5. Hercogová J, Ricceri F, Tripo L, Lotti T, Prignano F. Psoriasis and body mass index. Dermatol Ther. 2010 M;23:152-4.

6. Lee SY, Gallagher D. Assessment methods in human body composition. Curr Opin Clin Nutr Metab Care. 2008:11:566-72.

7. Heymsfield SB. Development of imaging methods to assess adiposity and metabolism. Int J Obes (Lond). 2008;32:S76-82.

8. Woodrow G. Body composition analisys techniques in the aged adult: indications and limitations. Curr Opin Clin Nutr Metab Care. 2009;12:8-14.

9. Albanese CV, Diessel E, Genant HK. Clinical applications of body composition measurements using DXA. J Clin Densitom. 2003;6:75-85.

10. Plank LD. Dual-energy $X$-ray absorptiometry and body composition. Curr Opin Clin Nutr Metab Care. 2005;8:305-9.

11. Kennedy AP, Shea JL, Sun G. Comparison of the classification of obesity by BMI vs. Dual-energy X-ray Absorptiometry in the Newfoundland population. Obesity (Silver Spring). 2009;17:2094-9.

12. Obesity: preventing and managing the global epidemic. Report of a WHO consultation. World Health Organ Tech Rep Ser. 2000;894:i-xii, 1-253.

13. Physical status: the use and interpretation of anthropometry. Report of a WHO Expert Committee. World Health Organ Tech Rep Ser. 1995;854:1-452.

14. Landis JR, Koch GG. The measurement of observer agreement for categorical data. Biometrics. 1977;33:159-74.

15. Pagano M, Gauvreau K. Princípios de bioestatística. São Paulo: Thomson; 2004.

16. www.who.int [Internet]. World Health Organization. Obesity and overweight: fact sheet No.311.2011 [cited 2014 Apr 8]. Available from: http://www.who.int/ mediacentre/factsheets/fs311/en/index.html

17. Brasil. Ministério da Saúde. Secretaria em Saúde. Departamento de Vigilância e agravos não Transmissíveis e Promoção de Saúde. Vigitel Brasil 2012: vigilância de fatores de risco e proteção para doenças crônicas por inquérito telefônico. Brasilia: Ministério da Saúde; 2013. 136 p. [acesso 4 Ago 2014]. Disponível em: http://www.sbpt.org.br/downloads/arquivos/vigitel_2012.pdf

18. Kim CR, Lee JH. An Observational study on the obesity and metabolic status of psoriasis patients. Ann Dermatol. 2013;25:440-4.

19. Carrascosa JM, Rocamora V, Fernandez-Torres RM, Jimenez-Puya R, Moreno $\mathrm{JC}$, Coll-Puigserver N, et al. Obesidad y psoriasis: natureza inflamatória de la obesidad, relación entre psoriasis y obesidade e implicaciones terapêuticas. Actas Dermo-Sif. 2014;105:31-44.

20. Wolk K, Mallbris L, Larsson P, Rosenblad A, Vingård E, Ståhle M. Excessive body weight and smoking associates with a high risk of onset of plaque psoriasis. Acta Derm Venereol. 2009;89:492-7.

21. Takahashi H, lizuka H. Psoriasis and metabolic syndrome. J Dermatol. 2012;39:212-8.

22. Gisondi P, Tessari G, Conti A, Piaserico S, Schianchi S, Peserico A, et al. Prevalence of metabolic syndrome in patients with psoriasis: a hospital-based case-control study. Br J Dermatol. 2007;157:68-73.

23. Love TJ, Qureshi AA, Karlson EW, Gelfand JM, Choi HK. Prevalence of the metabolic syndrome in psoriasis. Arch Dermatol. 2011;147:419-24.

24. Lauria MW, Moreira LM, Machado-Coelho GL, Neto RM, Soares MM, Ramos AV. Ability of body mass index to predict abnormal waist circumference: receiving operating characteristics analysis. Diabetol Metab Syndr. 2013;5:74.

25. Flegal KM, Shepherd JA, Looker AC, Graubard BI, Borrud LG, Ogden CL, et al. Comparisons of percentage body fat, body mass index, waist circumference, and waist-stature ratio in adults. Am J Clin Nutr. 2009;89:500-8.

26. Pietrobelli A, Tatò L. Body composition measurements: from the past to the future. Acta Paediatr Suppl. 2005;94:8-13.

27. Lukaski HC. Soft tissue composition and bone mineral status: evaluation by dualenergy X-ray absorptiometry. J Nutr. 1993;123:438-43.

28. Kumar $\mathrm{P}$, Thomas J. Comorbid conditions in psoriasis- Higher frequency in females: A prevalence study. Indian Dermatol Online J. 2012;3:105-8.
29. Davidovici BB, Sattar N, Prinz J, Puig L, Emery P, Barker JN, et al. Psoriasis and systemic inflammatory diseases: potential mechanistic links between skin disease and co-morbid conditions. J Invest Dermatol. 2010;130:1785-96.

30. Armstrong AW, Harskamp CT, Armstrong EJ. The association between psoriasis and obesity: a systematic review and meta-analysis of observational studies. Nutr Diabetes. 2012;2:e54.

31. Duarte GV, Follador I, Cavalheiro CM, Silva TS, Oliveira Mde F. Psoríase e obesidade: revisão de literatura e recomendações no manejo. An Bras Dermatol. 2010;85:355-60.

32. Solis MY, de Melo NS, Macedo ME, Carneiro FP, Sabbag CY, Lancha Júnior AH et al. Nutricional status and food intake of patients with systemic psoriasis and psoriatic arthritis associated. Einstein (Sao Paulo). 2012;10:44-52.

33. Ludwig RJ, Herzog C, Rostock A, Ochsendorf FR, Zollner TM, Thaci D, et al. Psoriasis: a possible risk factor for development of coronary artery calcification. Br J Dermatol. 2007:156:271-6.

34. Gelfand JM, Neimann AL, Shin DB, Wang X, Margolis DJ, Troxel AB. Risk of myocardial infarction in patients with psoriasis. JAMA. 2006;296:1735-41.

35. Gelfand JM, Dommasch ED, Shin DB, Azfar RS, Kurd SK, Wang X, et al. The risk of stroke in patients with psoriasis. J Invest Dermatol. 2009;129:2411-8.

\author{
MAILING ADDRESS: \\ Michelle dos Santos Diniz \\ Rua Domingos Vieira 488, Sala E9. \\ Bairro Santa Efigênia \\ 30150-240 - Belo Horizonte - MG \\ Brazil \\ E-mail: michellesdmi@yahoo.com.br
}

How to cite this article: Diniz MS, Bavoso NC, Kakehasi AM, Lauria MW, Soares MMS, Pinto JM. Assessment of adiposity in psoriatic patients by dual energy X-ray absorptiometry compared to conventional methods. An Bras Dermatol. 2016;91(2):150-5. 